\title{
CARACTERIZAÇÃO ESTRUTURAL E TERMOFÍSICA DE ARAMES DE LIGAS DE NITI COM MEMÓRIA DE FORMA *
}

\author{
Paulo Vinicius Pelegrini ${ }^{1}$ \\ Guilherme Nagatoshi Asakawa² \\ Mônica Aline Magalhães Gurge ${ }^{3}$ \\ Andersan dos Santos Paula ${ }^{4}$ \\ Alaelson Viera Gomes ${ }^{5}$ \\ Patrícia Freitas Rodrigues ${ }^{6}$ \\ Francisco Manuel Braz Fernandes ${ }^{7}$ \\ Shimeni Baptista Ribeiro ${ }^{8}$ \\ Edir Neves Teixeira ${ }^{9}$
}

\section{Resumo}

A partir de duas ligas de NiTi elaboradas em escala laboratorial e processadas via forjamento rotativo e fundição por sucção a vácuo (molde de cobre), suportados pelas análises de Microscopia Eletrônica de Varredura (MEV), Espectroscopia de Energia Dispersiva de Raio-X (EDS) e Calorimetria Diferencial de Varredura (DSC), foi possível observar que a fundição por sucção a vácuo resultou no mais significativo refinamento microestrutural e aparente homogeneidade microestrutural/ composicional, exibindo transformações de fase por DSC como fundida.

Palavras-chave: Ligas de NiTi; Ligas com memória de Forma; DSC; MEV/EDS.

\section{STRUCTURAL AND THERMOPHYSICAL CHARACTERIZATION OF NITI SHAPE MEMORY ALLOYS WIRES}

\section{Abstract}

From two NiTi alloys elaborated in laboratory scale and processed by rotary forging, and vaccum suction casting (copper molded), supported by the analyses of scanning electronic microscopy (SEM), energy dispersive X-ray spectroscopy (EDS) and Differential Scanning Calorimetry (DSC), was possible to observe that the vaccum suction casting resulted on the most significant microstructural refinement and apparent greater microstructural/compositional homogeneity, exhibiting phase transformations by DSC as casting.

Keywords: NiTi alloys; Shape memory alloy; DSC; MEV/EDS.

1 Graduando em Eng. Metalúrgica, Seção de Engenharia de Mecânica e Materiais (SE/4), Instituto Militar de Engenharia (IME), Rio de Janeiro, RJ, Brasil.

2 Eng ${ }^{\circ}$ Metalurgista graduado no IME, Rio de Janeiro, RJ, Brasil.

3 M.Sc., Enga Metalurgista, Doutoranda em Ciência dos Materiais do Programa de Pós-Graduação em Ciência dos Materiais (PGCM), SE-4, IME, Rio de Janeiro, RJ, Brasil.

4 D.Sc., M.Sc., Enga Metalurgista, Professora Adjunta do PGCM e da Graduação, SE-4, IME, Rio de Janeiro, RJ, Brasil.

5 D.Sc., M.Sc., Engo Metalurgista, Professor Adjunto do PGCM e da Graduação, SE-4, IME, Rio de Janeiro, RJ, Brasil.

6 M.Sc., Química Industrial, Doutoranda em Ciência dos Materiais, Centro de Investigação de Materiais (CENIMAT/i3N), Departamento de Ciência dos Materiais (DCM), Faculdade de Ciência e Tecnologia (FCT), Universidade Nova de Lisboa (UNL), Caparica, Portugal.

7 D.Sc., M.Sc., Engenheiro Mecânico, Professor Associado, CENIMAT/i3N / DCM / FCT / UNL, Caparica, Portugal.

8 Eng ${ }^{a}$ Metalurgista, M.Sc., D.Sc., Professora, UniFOA, Volta Redonda, RJ, Brasil

9 Eng ${ }^{o}$ Metalurgista, M.Sc., Professor, UniFOA, Volta Redonda, RJ, Brasil. 


\section{INTRODUÇÃO}

Em materiais que apresentam transformação martensítica termoelástica podem ser verificados dois efeitos: pseudoelasticidade e efeito memória de forma. As ligas com memória de forma são ligas capazes de retornar a forma ou tamanho previamente definido quando submetidas a um tratamento térmico apropriado [1,2].

O efeito memória de forma é a "memorização" de uma determinada forma anterior a uma deformação do material no campo de estabilidade da fase martensítica, seguida por um aquecimento da liga, até o campo de estabilidade da fase mãe, que proporciona o retorno à forma "memorizada". Isso ocorre quando, na deformação, não há deslizamento de discordâncias, num campo de temperatura abaixo da final para transformação martensítica (Mf) e conserva esta deformação após a remoção da carga. No entanto, se for aquecido acima da temperatura de completa reversão (Af), a fase mãe retornará completamente à forma inicialmente memorizada.

Já a pseudoelasticidade se faz presente em um campo de temperatura acima da temperatura de início da transformação de formação da fase mãe (Ai), abrangendo a superelasticidade (SE) e efeito elástico similar ao da "borracha". No intervalo Ai e Af, o efeito memória de forma e a superelasticidade se sobrepõem, pela coexistência da fase mãe e do produto da transformação martensítica, isto é, este intervalo compreende o comportamento elástico da "borracha" onde ocorre uma grande recuperação com a remoção da carga, sob condição isotérmica, retornando parcialmente à condição original. Enquanto a superelasticidade está associada a transformação martensítica induzida por tensão. A mesma dá-se acima de Af, quando se deforma a fase mãe sob condições em que a tensão necessária para induzir a transformação martensítica é a inferior aquela para ter-se a deformação por deslizamento de discordâncias, cessada a deformação e removida a carga a transformação se reverte a condição estrutural da fase mãe de origem.

Dentre estes materiais, faz-se presente as ligas NiTi, as quais apresentam alta resistência mecânica, à fadiga e à corrosão, boa ductilidade e biocompatibilidade, isso se for comparada com outras ligas com memória de forma. As temperaturas de transformação de fase em ligas NiTi ricas em $\mathrm{Ni}$ são observadas abaixo da temperatura ambiente, sendo geralmente superelásticas à temperatura ambiente [3]. Essas ligas apresentam a formação de até três tipos de fases, austenita (B2 - mais alta temperatura - cúbica do tipo $\mathrm{CsCl}$ ), fase $\mathrm{R}$ (martensita - temperaturas intermediárias - trigonal com distorção romboédrica no ângulo $\alpha$ ) e martensita (B19' - mais baixa temperatura - monoclínica) [1].

Um grande desafio na produção dessa liga de NiTi é o controle composicional, principalmente na redução de impurezas, tais como carbono e oxigênio. A presença de carbetos e óxidos de titânio e níquel indica mudanças nas propriedades das ligas de $\mathrm{NiTi}$, influenciando a transformação martensítica, a fluidez e os efeitos de memória de forma e pseudoelasticidade presentes na liga [1,3,4]. Além disso, a forma como essas inclusões estão presentes na matriz e sua geometria também influenciam nas propriedades da liga $[1,3,4]$.

O processo de fusão aplicado neste estudo é o VIM (fusão em forno de indução à vácuo), que promove a fusão do material pelo aquecimento por indução de alta frequência em vácuo ou gás inerte, neste estudo em vácuo, com uso de um cadinho de grafite. Outro processo de fusão é o VAR (refusão à arco elétrico, com eletrodo não consumível e cadinho de cobre refrigerado com água), que foi usado para refundir lingotes menores com atmosfera de argônio até os estágios finais do 
processo termomecânico (envolvendo forjamento rotativo a quente e a frio) para obtenção de fios de $3 \mathrm{~mm}$ de diâmetro.

O presente trabalho visou comparar a evolução estrutural e termofísica (temperaturas de transformação de fase) para obtenção de arames de $3 \mathrm{~mm}$ a partir de uma liga de $\mathrm{NiTi}$ rica em $\mathrm{Ni}$ elaborado pelo processo VIM e posteriormente refundido em pequenos lingotes para o processo de forjamento rotativo (inicialmente a quente e nas etapas finais a frio) e fundição por sucção a vácuo. Este estudo foi incialmente conduzido no âmbito de um trabalho de conclusão de curso de Engenharia Metalúrgica do Instituto Militar de Engenharia (IME), pelo aluno e agora engenheiro G.N. Asakawa [6], e dado continuidade através do estudo realizado no âmbito da disciplina de Iniciação a Pesquisa, desde mesmo curso e instituição, pelo aluno P.V. Pelegrini.

\section{MATERIAIS E MÉTODOS}

\subsection{Materiais}

Os materiais em estudo são provenientes de duas ligas de NiTi elaboradas pelo professor e pesquisador Dr. Jorge Otubo do Instituto Tecnológica da Aeronáutica (ITA), Brasil.

As ligas foram produzidas pelo processo de fusão por indução (VIM) à vácuo, que gerou lingotes chamados de VIM 47 e VIM 74. No caso do Lingote VIM 47 foi adicionado uma maior quantidade em peso de $\mathrm{Ti}$ objetivando uma liga rica em $\mathrm{Ti}$ (50,70\%at.Ti, 45,62\%p.Ti - percentual total de titânio objetivado), enquanto no lingote VIM 74 foi adicionado uma maior quantidade em peso de Ni objetivando uma liga rica em $\mathrm{Ni}$ (50,8\%at. $\mathrm{Ni}, 55,86 \%$ p. $\mathrm{Ni}$ - percentual total de níquel objetivado). Termos dimensionais, os lingotes provenientes do forno VIM tinham $90 \mathrm{~mm}$ de diâmetro e $300 \mathrm{~mm}$ de altura, com peso de $20 \mathrm{~kg}$.

\subsection{Métodos}

\subsubsection{Processamento}

Os materiais foram submetidos a duas rotas distintas de processamento a fim de obter um arame de $3 \mathrm{~mm}$ de diâmetro, onde:

- uma rota deu-se por processamento termomecânico via forjamento rotativo (inicialmente a quente e posteriormente a frio), partindo de uma porção de aproximadamente $90 \mathrm{~g}$ do lingote VIM (de ambas as ligas, separadamente) refundido em um forno de fusão a arco elétrico (atmosfera de argônio, eletrodo não consumível e cadinho de cobre refrigerado a água - forno projetado no ITA). No forjamento rotativo o material foi submetido inicialmente a 4 passes de forjamento a quente e 2 passes finais de forjamento a frio, com troca de ferramenta a cada a passe a fim de prover a redução gradativa do diâmetro do material processado. Antecedendo cada etapa de deformação a quente as amostras foram aquecidas em forno tipo Mufla a $800^{\circ} \mathrm{C}$ (30 minutos antes da primeira etapa e 10 minutos antes das demais), seguido de resfriamento ao ar após a deformação e uso de retifica manual para remoção de defeitos superficiais antes de retorno ao forno. O objetivo desta temperatura de reaquecimento foi ter o material num campo de temperatura onde a resistência a deformação fosse menor, de modo a obter-se maiores reduções por passe. Antes de cada uma das etapas de deformação a frio o material foi 
solubilizado a uma temperatura de $800^{\circ} \mathrm{C}$ por 10 minutos, seguido de resfriamento em água, de modo a promover comitantemente a dissolução de precipitados e recristalização da matriz previamente encruada.

- a outra rota deu-se por processo de fundição por sucção a vácuo (molde de cobre refrigerado com água), partindo de uma porção de aproximadamente $20 \mathrm{~g}$ do lingote VIM (de ambas as ligas, separadamente) refundido em um forno de fusão a arco elétrico (atmosfera de argônio, eletrodo de tungstênio não consumível e cadinho de cobre refrigerado a água) contendo sistema interligado ao cadinho de fusão para processo direto de fundição por sucção a vácuo - forno "Arc Melter AM plus suction" projetado pela empresa - Edmund Bühler $\mathrm{GmbH}$, instalado nos laboratórios do Departamento de Engenharia Mecânica da Universidade Politécnica de Timisoara (UPT), Romênia.

\subsubsection{Analises Termofísica e Microestrutural}

De posse das amostras oriundas das etapas iniciais e finais descritas abaixo, foram conduzidas análises apresentadas neste artigo:

- refundida no forno VAR do ITA

- final do processamento de forjamento rotativo

- final da fundição por sucção a vácuo

\subsubsection{Calorimetria diferencial de varredura (DSC)}

As amostras para análise de DSC foram extraídas por corte de precisão, objetivando massa de $30 \mathrm{mg}$, das condições de processamento selecionadas para o estudo. Posteriormente foram decapadas em uma solução ácida contendo $45 \mathrm{ml}$ de $\mathrm{HNO}_{3}$, $45 \mathrm{ml}$ de $\mathrm{H}_{2} \mathrm{O}$ e $10 \mathrm{ml}$ de $\mathrm{HF}$ por uma hora, com o intuito de remover a camada superficial deformada pelo corte e oxidação superficial, obtendo por fim amostra com massa próxima $20 \mathrm{mg}$.

Para as análises de DSC foi utilizado um equipamento Netzsch modelo F401, Proteus, com forno de baixa temperatura $\left(-150^{\circ} \mathrm{C}\right.$ a $\left.600^{\circ} \mathrm{C}\right)$, instalado no Centro de Investigação de Materiais (CENIMAT), na Faculdade de Ciências e Tecnologia da Universidade Nova de Lisboa. Foram adotados ciclos térmicos entre $-150^{\circ} \mathrm{C}$ e $150^{\circ} \mathrm{C}$ e taxa de aquecimento e resfriamento de $10^{\circ} \mathrm{C} / \mathrm{min}$, com atmosfera protetiva de gás nitrogênio. As temperaturas de início e fim das transformações de fase foram obtidas a partir dos gráficos gerados pelos ensaios de cada uma das amostras nas distintas etapas do processamento em estudo, fazendo uso do método clássico de cruzamento das retas associadas à linha base de cada pico de transformação e regiões lineares antes e após a temperatura de pico.

\subsubsection{Microscopia eletrônica de varredura (MEV)}

De forma similar a análise de DSC, as amostras para MEV foram extraídas por meio de um processo de corte abrasivo em uma máquina de corte de precisão com o auxílio de disco diamantado. Após o corte, a face da seção transversal a ser analisada de cada amostra foi submetida a lixamento com auxílio de uma lixadeira rotativa manual com lixas de carbeto de silício até 2400 mesh. Após a etapa de lixamento, foi feito um polimento eletrolítico com uma solução composta por $20 \%$ de ácido sulfúrico e $80 \%$ de metanol à temperatura ambiente por aproximadamente 15 a $20 \mathrm{~s}$ e sob tensão de $20 \mathrm{~V}$. Após o polimento, as amostras foram analisadas no 
MEV. Posteriormente, as amostras sofreram ataque químico para revelar os contornos de grãos austeníticos e cristais de martensita com solução de $50 \mathrm{ml}$ de glicerina (também conhecida como glicerol $\left(\mathrm{C}_{2} \mathrm{H}_{4} \mathrm{O}_{2}\right)$ ), $20 \mathrm{ml}$ de ácido nítrico concentrado $\left(\mathrm{HNO}_{3}\right)$ e $16 \mathrm{ml}$ de ácido fluorídrico concentrado (HF) durante 7 minutos e novamente foram analisadas no MEV. A preparação metalográfica e a análise no MEV foram feitas no laboratório de Microscopia Eletrônica do Instituto Militar de Engenharia com uso de um MEV FEI modelo Quanta 250 FEG, com filamento de emissão de campo (FEG), com auxílio dos detectores de elétrons secundários, de elétrons retroespalhados e espectrômetro de energia dispersiva de Raios-X (EDS) com tensão de $20 \mathrm{kV}$, spot size de 4,5 e WD próximo a $10 \mathrm{~mm}$.

\section{RESULTADOS E DISCUSSÃO}

Gráficos de DSC das amostras VIM 47 e VIM 74 encontram-se representados nas Figuras 1 e 2, respectivamente. Enquanto as respectivas temperaturas e sequências de transformação de fase obtidas a partir das curvas de DSC (Figuras 1 e 2) para as diferentes amostras do material em estudo são numericamente mostradas na Tabela 1.

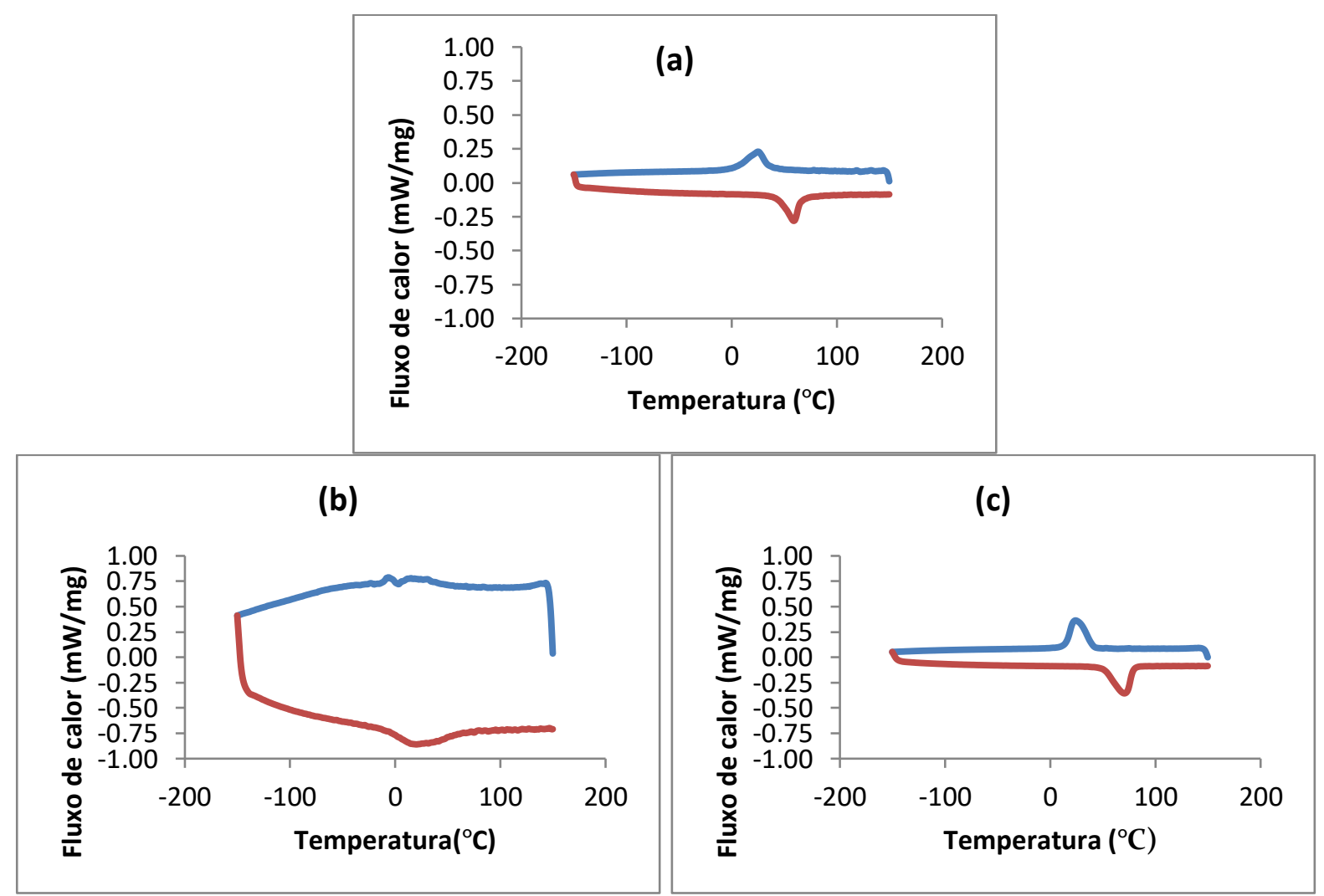

Figura 1. Curvas de DSC da liga VIM 47 nas condições: (a) Refusão (VAR) ITA; (b) arame Forjamento rotativo (FR); (c) arame Fundição por sucção a vácuo (FSV) ponta. 

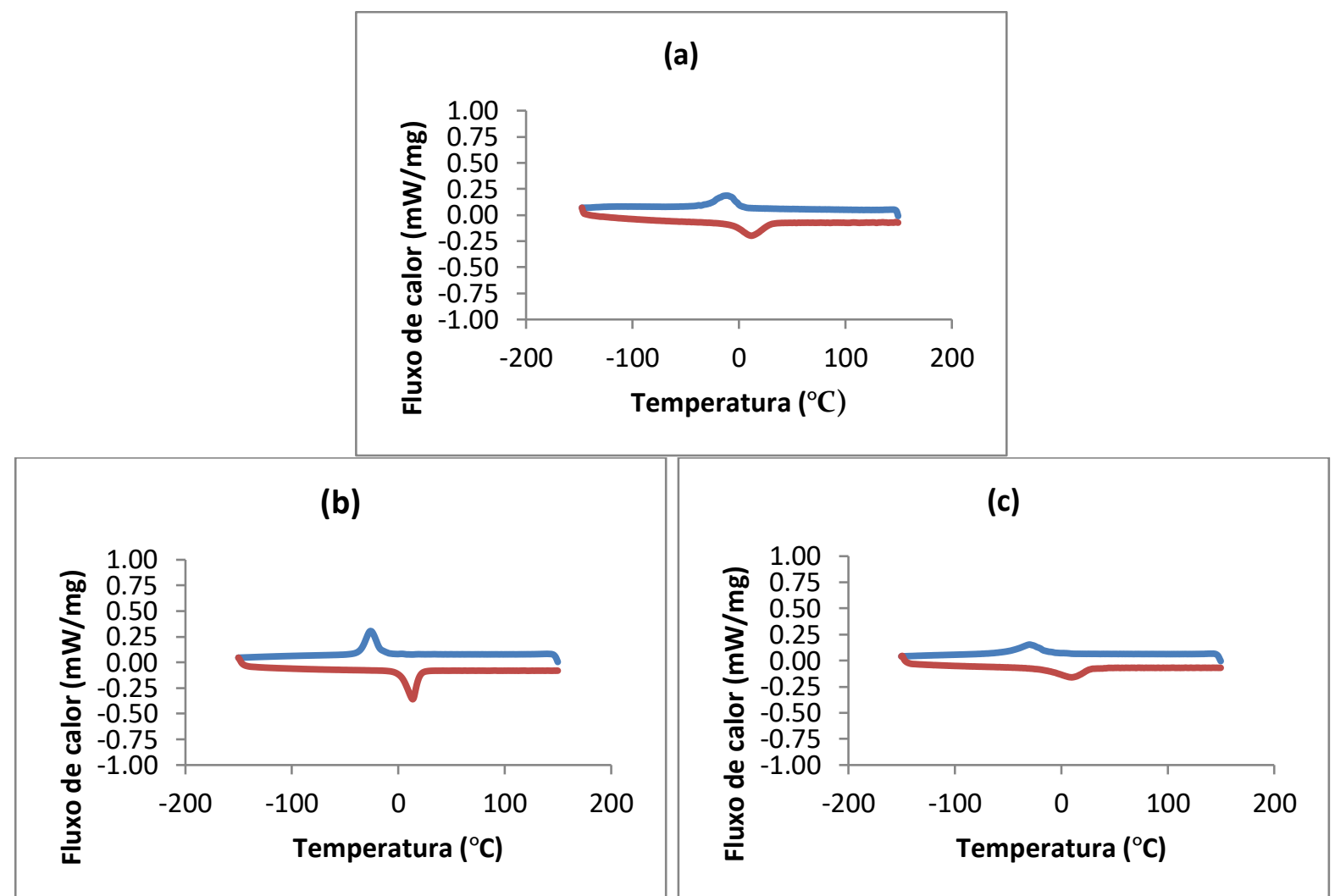

Figura 2. Curvas de DSC da liga VIM 74 nas condições: (a) Refusão (VAR) ITA (b) arame Forjamento rotativo (FR); (c) arame Fundição por sucção a vácuo (FSV) ponta.

Tabela 1. Valores das temperaturas de transformação de fase.

\begin{tabular}{|c|c|c|c|c|c|c|c|}
\hline $\begin{array}{c}\text { Temperaturas } \\
\left({ }^{\circ} \mathbf{C}\right)\end{array}$ & \multicolumn{3}{|c|}{ Pico Resfriamento } & \multicolumn{3}{c|}{ Pico aquecimento } & \multirow{2}{*}{ Fase Tamb* } \\
\cline { 2 - 7 } & $\mathbf{M i}$ & $\mathbf{M p}$ & $\mathbf{M f}$ & $\mathbf{A i}$ & $\mathbf{A p}$ & $\mathbf{A f}$ & \\
\hline VIM47(VAR ITA) & 39 & 1 & 25 & 42 & 59 & 68 & B2 e B19' \\
\hline VIM47(FR) & 60 & 12 & -15 & -5 & 16 & 62 & B2, R e/ou B19' \\
\hline VIM47(FSV) & 42 & 21 & 11 & 45 & 66 & 81 & B2, B19' e/ou R \\
\hline VIM74(VAR ITA) & 8 & -13 & -35 & -9 & 12 & 31 & B2 \\
\hline VIM74(FR) & -13 & -26 & -40 & 0 & 13 & 23 & B2 \\
\hline VIM74(FSV) & -15 & -29 & -44 & -2 & 11 & 22 & B2 \\
\hline
\end{tabular}

${ }^{*}$ Considerando a amostra resfriada até temperatura ambiente após referida etapa de processamento.

Na Tabela 1 encontram-se em negrito FR e FSV do VIM 47 e do VIM 74, resultados obtidos neste trabalho, e enquanto os demais (sobreposto a FR) foram mensurados no trabalho de conclusão de curso de G.N. Asakawa [6]. Onde são apresentadas as temperaturas da transformação martensítica $\left(M_{i}\right.$ - Temperatura de Início, $A_{p}-$ Temperatura de Pico e $A_{f}$ - Temperatura de Fim de Transformação) e da transformação reversa $\left(A_{i}-\right.$ Temperatura Inicial da Transformação Austenítica, $A_{p}-$ Temperatura Correspondente e $A_{f}$ - Temperatura Final de Transformação da Austenítica). Pode-se observar na análise de DSC picos de transformação de fase martensítica (resfriamento) e reversa (aquecimento) de ambas as ligas refundidas no forno VAR do ITA (Figuras 1a e 2a). Enquanto que nas condições finais dos 2 processamentos em estudo, todas apresentaram picos de transformação de fase martensítica e reversa, exceto a amostra da liga VIM47 do final do forjamento rotativo que não apresentou picos definidos. Este comportamento pode ser devido composição da liga, que pode ser rica em Ti apresenta-se martensítica a 
temperatura ambiente e com isto o percentual de deformação a frio no final do forjamento imposto a ambas foi capaz de encruar significativamente a martensita presente na VIM47 suprimindo quase que totalmente as transformações, mas não encruar tão significativamente a austenita que provavelmente se fazia presente na VIM74 antes desta última etapa de processo. Por fim, as amostras provenientes da fundição por sucção a vácuo, ou seja simplesmente fundidas, em ambos os casos apresentaram picos de transformação de fase martensítica e reversa. No entanto, as áreas dos picos apresentaram-se maiores para a liga VIM47. Como a fundição por sucção a vácuo deu-se num molde de cobre refrigerada com água com somente 3 $\mathrm{mm}$ de diâmetro interno, as taxas de resfriamento impostas foram bem altas na solidificação das ligas líquidas para formar diretamente os arames de $3 \mathrm{~mm}$. Este fator deve ter afetado a homogeneidade composicional do produto fundido por sucção, como é relatado na literatura por trabalhos de Hongjie Jiang et al. [7] associado ao efeito da taxa de resfriamento na microestrutura e propriedades termofísicas de produtos fundidos.

Nas Figuras 3, 4 e 5 são apresentadas as imagens das microestruturas observadas no MEV (elétrons secundários) das amostras selecionadas para o estudo neste trabalho após polimento eletrolítico (amostras somente refundidas) e ataque para revelar os contornos de grãos e entre fases (amostras das condições finais dos dois processamentos).
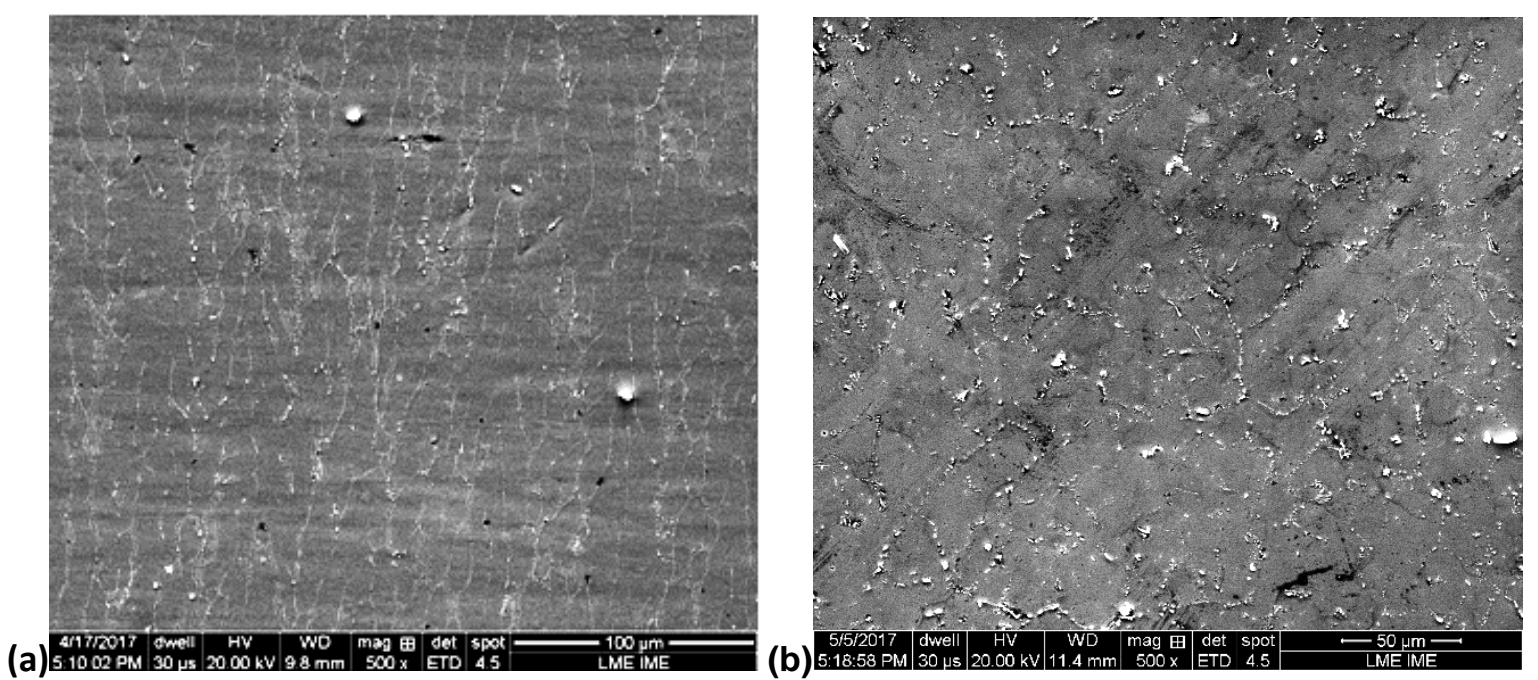

Figura 3. Imagens obtidas com detector de elétrons secundários / MEV amostras após polimento eletrolítico e ataque para revelar a microestrutura: a) VIM 47 VAR ITA; b) VIM 74 VAR ITA.

A microestrutura das ligas resultantes simplesmente da refusão no forno VAR do ITA (Figura 3), revelam a grãos da matriz metálica (áreas escuras) circundados por partículas (áreas mais claras). Com base nas análises pontuais de EDS estas partículas estariam relacionadas a inclusões advindas do processo de fusão em forno VIM, por estarem associadas a Ti, C, O e $\mathrm{Ni}$ em teores menos elevados,

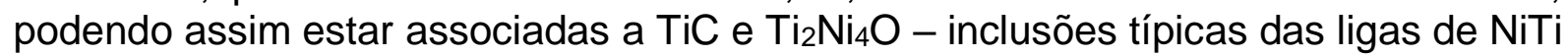
elaboradas em forno de indução a vácuo (VIM) com cadinho de grafite $[3,4,8]$. No entanto a liga VIM47 apresenta grãos com aspecto tendendo a coluna, e a VIM74 com aspecto tendendo a equiaxial.

Ao se observar as microestruturas das duas condições finais de processamento em estudo, nota-se uma mudança significativa do aspecto microestrutural quanto comparado ao da condição simplesmente refundidas em ambas as ligas. Na liga VIM47 (Figura 4 a,b), tanto no forjamento rotativo (FR) como na fundição por sucção 
a vácuo (FSV), observa-se contornos de grão contendo agulhas (alguns que se cruzam) no seu interior, sendo que no interior o tamanho de grão é mais refinado na FSV e quantidade de mais agulhas juntamente com grão alongado na FR. Enquanto na liga VIM74, em ambas as condições, observa-se aspectos com algumas diferenças das vista nas amostras de VIM47, onde:

- na FR os grãos têm aspecto equiaxiais, contendo linhas paralelas no interior somente no interior de alguns dos grãos.

- na FSV os grãos aparentam se ligeiramente menores que com seu interior liso.

(a)

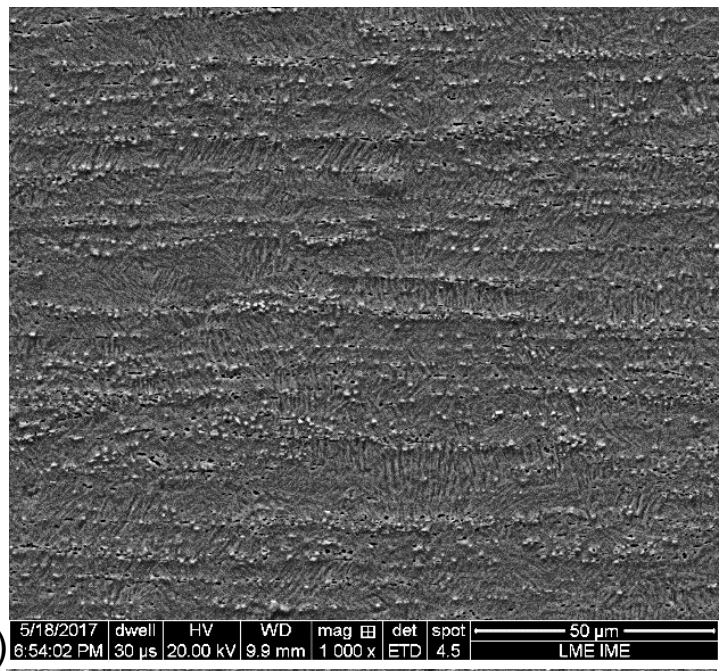

(c)

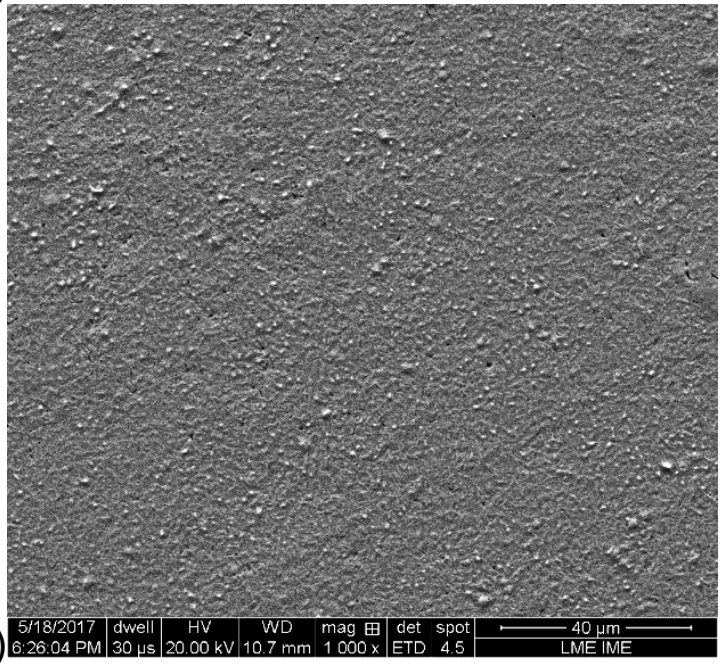

(b)
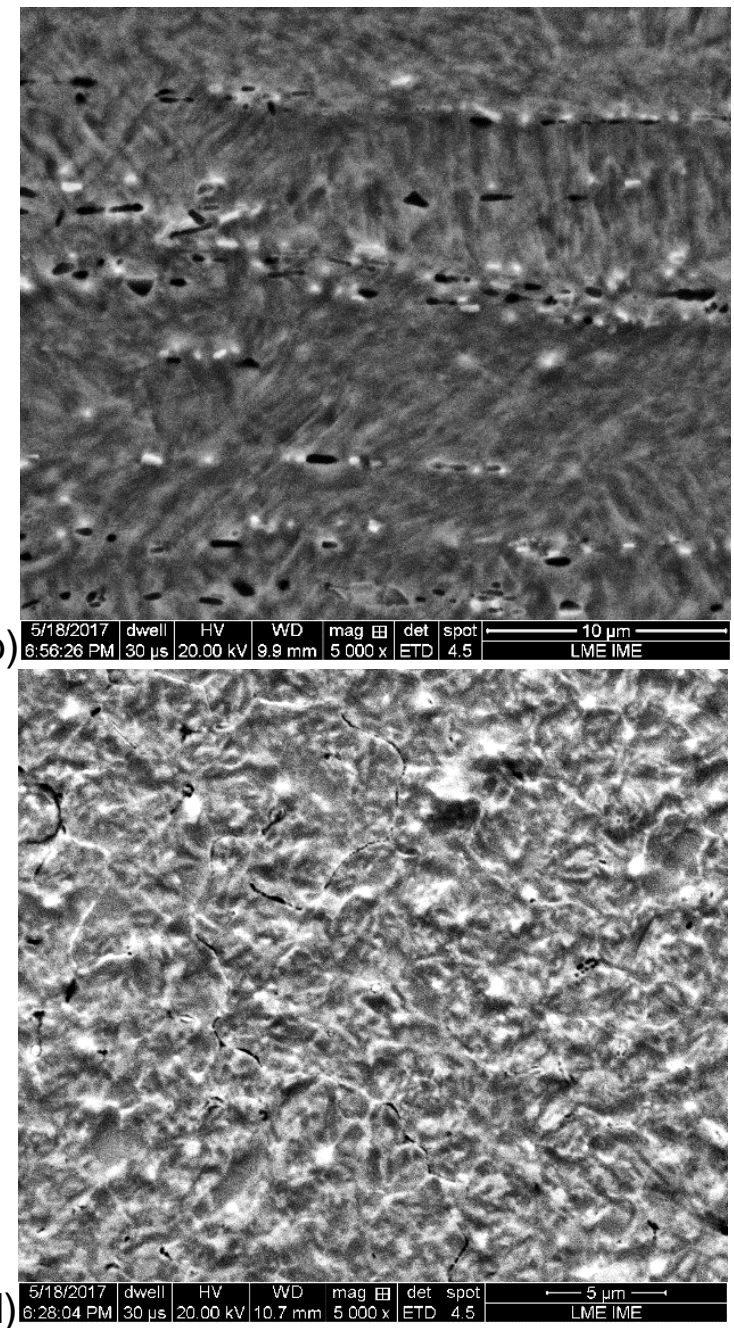

Figura 4. Imagens obtidas com detector de elétrons secundários / MEV amostras após polimento eletrolítico e ataque para revelar a microestrutura: (a,b) VIM 47 FR; (c,d) VIM 47 FSV.

As razões para as diferenças de aspecto microestruturais entre as amostras de uma mesma liga e condições de processamento diferentes, ou de uma mesma condição de processamento e ligas diferentes, podem estar associadas a:

- a liga VIM47 revelou por DSC ser parcialmente martensítica a temperatura ambiente (considerando a curva do resfriamento) tanto para FR como para FSV, ou seja com um misto de B2 e B19' e/ou R, o que justificativa a presença das agulhas associadas a fase de natureza martensítica;

- os grãos alongados e agulhas no seu interior que caracterizam a amostra VIM47FR podem ser justificados pela composição da liga (mais enriquecida em Ti), deformação a temperatura ambiente no campo de estabilidade de B2 e B19', com base nos indicativos de temperaturas de transformação da condição refundida 
VIM47 VAR ITA (Figura 2 e Tabela 1), durante a última etapa de forjamento rotativo, resultando assim numa supressão parcial das transformações de fases (justificativa para os picos de DSC pouco definidos), alongando os contornos de grão prévios de B2. Levando a coexistência de B2 e R e/ou também B19' a temperatura ambiente.

- os grãos aparentemente equiaxiais e agulhas o seu interior que caracterizam a amostras VIM47FSV, podem ser justificados pela composição da liga (mais enriquecida em Ti), ausência de componentes mecânica de deformação e tensões residuais resultantes da taxa de resfriamento elevada durante a solidificação da liga na cavidade do molde associada a fundição por sucção a vácuo, levando a uma matriz metálica mais homogênea apta a exibir transformação de fases nas condição somente fundida (justificativa para os picos de DSC definidos). Levando assim a coexistência de B2 e B19' e/ou também R a temperatura ambiente.

(a)
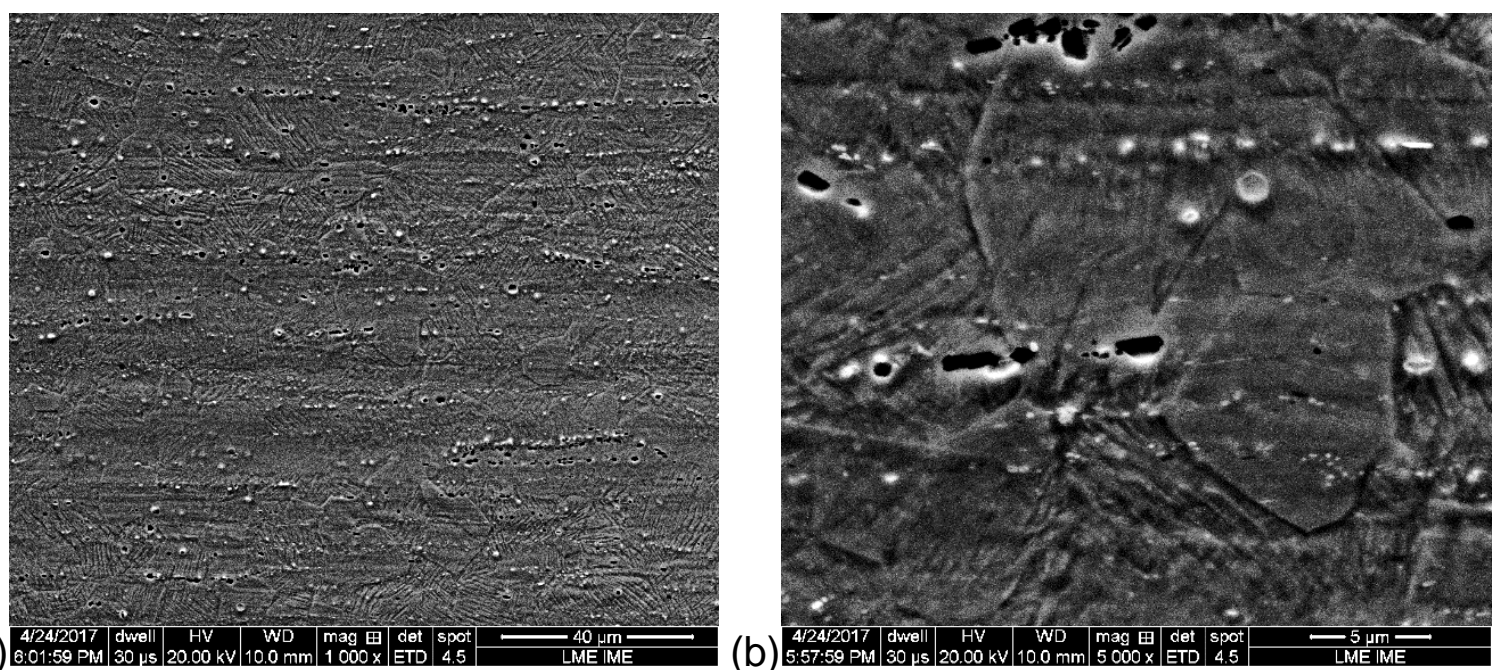

(c)
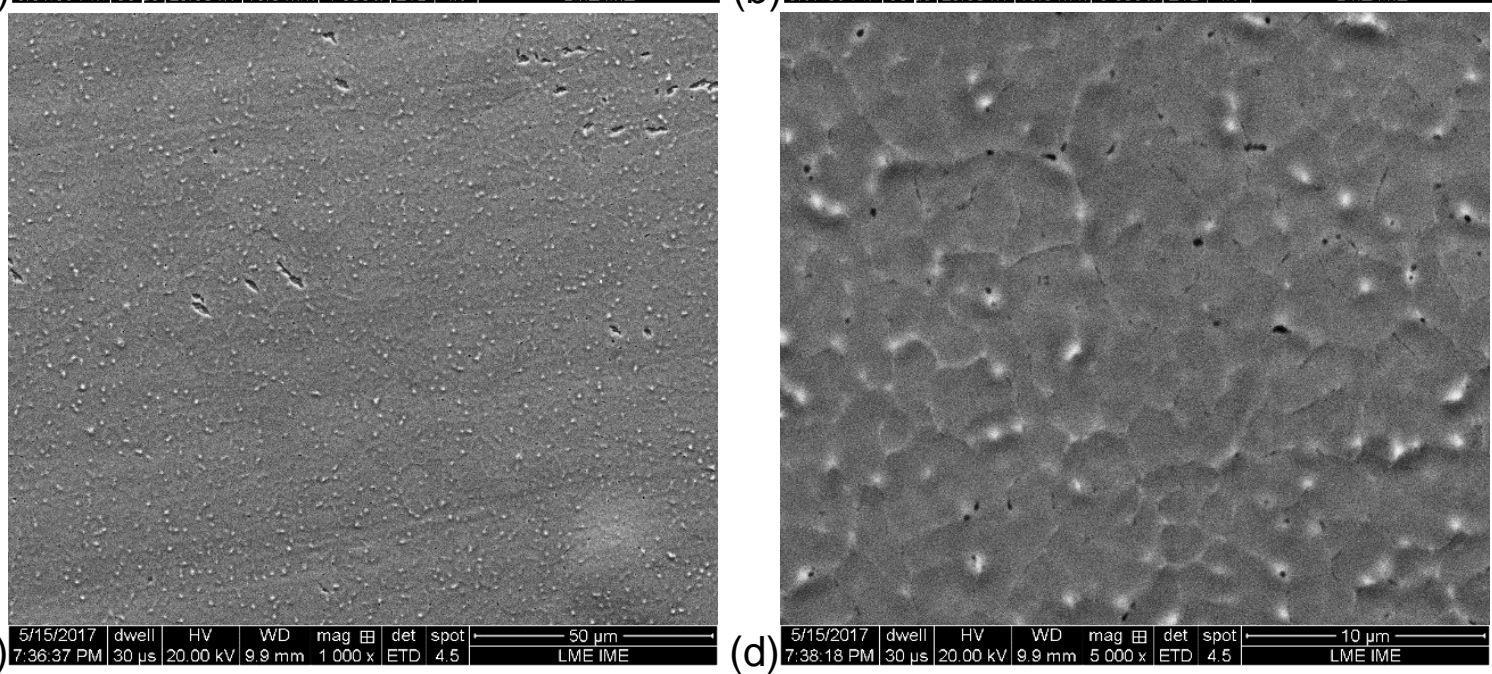

Figura 5. Imagens obtidas com detector de elétrons secundários / MEV amostras após polimento eletrolítico e ataque para revelar a microestrutura: (a,b) VIM 74 FR; (c,d) VIM 74 FSV.

Por outro lado, para a liga VIM74, as características microestruturais:

- grãos equiaxiais e agulhas no interior de alguns destes para a amostra VIM74FR, pode ser justificado pela composição da liga (mais enriquecida em Ni); deformação a temperatura ambiente em provável campo de estabilidade de B2, com base nos indicativos de temperaturas de transformação da condição refundida VIM74 VAR ITA (Figura 2 e Tabela 1) com algum encruamento parcial, resultando no aumento das 
tensões residuais dificultando o início da transformação martensítica e promovendo a estabilização de B2 a temperatura ambiente;

- grãos equiaxiais com seu interior liso para a amostra VIM74FV, pode ser justificado pela composição da liga (mais enriquecida em $\mathrm{Ni}$ ), ausência de componente mecânica de deformação, tensões residuais resultantes da taxa de resfriamento elevada durante a solidificação na cavidade do molde associada a fundição por sucção a vácuo, levando a uma matriz metálica mais homogênea apta a exibir transformações de fase na condição somente fundida (justificativa para os picos de DSC definidos). Levando assim a estabilidade de B2 a temperatura ambiente e deslocamento das temperaturas de transformação martensítica para valores mais baixos a condição refundida VAR ITA.

Observou-se também na microestrutura dos arames forjados e fundidos por sucção a presença das inclusões de mesma natureza química (baseados em resultados de análise de EDS - detectou-se $\mathrm{Ti}, \mathrm{C}, \mathrm{O}$ e traços de $\mathrm{Ni}$ ) daquelas observados nas condições refundidas no forno VAR ITA. No entanto as inclusões apresentaram alinhadas na direção de trabalho do forjamento rotativo e dispersas no fundição por sucção, junto as regiões de contorno de grão (pontos claros - Figuras 4 e 5). Para além de terem seu tamanho fragmentado pela componente mecânica deformação no forjamento (iniciados com etapas a quente e concluído com etapas a frio) e pela alta taxa de resfriamento na fundição por sucção. Outro detalhe observado no material fundido por sucção a vácuo é a presença de porosidades em regiões de contorno de grão, as quais devem estar associadas a gases adsorvidos no metal líquido que não tem tempo de ser liberados o processo de solidificação pela alta taxa de resfriamento imposta $[7,8]$.

Como a continuidade desse estudo, foi realizado por Teixeira [9] para a liga VIM74 forjada, pretende-se realizar um estudo quanto a otimização da solubilização e/ou envelhecimento na sua condição de fundição por sução a vácuo, e ambas as condições da liga VIM47.

\section{CONCLUSÃO}

Com base nos resultados apresentados para as duas ligas de $\mathrm{NiTi}$ em estudo e discussão realizada:

- tanto o processamento termomecânico de forjamento rotativo como a fundição por sucção a vácuo na produção de arames de $3 \mathrm{~mm}$ resultam em um refinamento microestrutural quando comparado ao produto fundido convencional. No entanto, o refinamento microestrutural da fundição por sucção à vácuo é muito mais significativo;

- em função da composição química de cada liga, em termos de percentual de Ni e $\mathrm{Ti}$, foi possível obter produtos com distintas características termofísicas em termos de sequência de transformação de fase como de temperaturas de transformação, e por consequência fases estáveis a temperatura ambiente;

- as inclusões presentes nos produtos finais de processamento tiveram seus tamanhos reduzidos, no forjamento por fragmentação e na fundição por sucção a vácuo devido a taxa de resfriamento imposta ao líquido fundido em molde de cobre refrigerado com água, sendo que neste último a redução da granulometria foi muito mais acentuada.

- o produto fundido por sucção apresentou microporosidades principalmente associadas a regiões junto aos contornos de grão. 


\section{Agradecimentos}

Os autores agradecem ao Professor J. Otubo e sua equipe, pela doação do material de partida e pelo apoio e uso da infraestrutura do Instituto Tecnológico da Aeronáutica (ITA) para realização da fusão e do processamento de forjamento deste trabalho.

A projeto MIDAS. Como também ao professor Corneliu Craciunescu pela refusão no forno VAR da Departamento de Engenharia Mecânica (DEM) da Universidade Politécnica de Timisoara (UPT), através dos recursos do Projeto MIDAS fomentado pelo o programa Europeu de Ações Marie Curie.

P.F.R e F.M.B.F reconhecem o financiamento da CENIMAT / i3N.

Ao IME pelos recursos para preparação e caracterização microestrutural. Ao Laboratório de Caracterização de Materiais Multiusuários no Instituto de Ciências Exatas (ICEx) da UFF pela disponibilização de uso do ultramicrodurômetro instrumentado. R.S. Teixeira agradece a bolsa de mestrado subsidiada pela CNPq vinculada ao PGCM/SE4-IME.

A.S.P. agracede a bolsa de produtividade à pesquisa (PQ-2) do CNPq (Processo 307798/2015-1).

P.V. Pelegrini agradece a R.S. Teixeira e F.S. Santos por toda ajuda e apoio quanto a etapa de aprendizagem da preparação metalográfica das amostras para análise no MEV.

\section{REFERÊNCIAS}

1 Otsuka K, Ren X. Physical metallurgy of Ti-Ni-based shape memory alloys, Prog. Mater. Sci. 2005, 516, 669.

2 Paula AS. Tratamentos termomecânicos de ligas do sistema $\mathrm{Ni}$-Ti [Tese de Doutorado]. Lisboa: Universidade Nova Lisboa - UNL/FCT; 2006.

3 Otubo J, Rigo OD, Coelho AA, Neto CM, Mei PR. The influence of carbon and oxygen content on the martensitic transformation temperatures and enthalpies of NiTi shape memory alloy, Mater. Sci. Eng. A 2008, 481-482, 639.

4 Otubo J, Rigo OD, Neto CM, Mei PR. The effects of vacuum induction melting and electron beam melting techniques on the purity of NiTi shape memory alloys, Mater. Sci. Eng. A 2006, 679, 2006.

5 Dieter GE. Mechanical Metallurgy, New York: McGraw-Hill,1986.

6 Asakawa GN. Processamento, Caracterizaçao e Estudo das Propriedades Funcionais de Ligas de NiTi com Efeito Memória de Forma [Trabalho de Conclusao de Curso de Engenharia Metalúrgica]. Rio de Janeiro: Instituto Militar de Engenharia - IME; 2016.

7 Jiang H, Cao S, Ke C, Ma X, Zhang X. Fine-Grained Bulk NiTi Shape Memory Alloy Fabricated by Rapid Solidification Process and Its Mechanical Properties and Damping Performance. J. Mater. Sci. Technol., 2013, 29(9), 855-862.

8 Kocich R, Szurman I, Kursa M. Shape Memory Alloys - Processing, Characterization and Applications. Chapter 2: The Methods of Preparation of Ti$\mathrm{Ni}-\mathrm{X}$ Alloys and Their Forming. book edited by Francisco Manuel Braz Fernandes, Intech, 2013.

9 Teixeira EN. Otimização das Condições dos Tratamentos Térmicos de 
Solubilização e Envelhecimento em Arame Forjado de Liga de NiTi Rica em Ni Para Aplicações Superelásticas [Dissertação de Mestrado]. Volta Redonda: Universidade Federal Fluminense - PPGEM; 2012. 